\title{
Pathological effects of Helleborus Orientalis used in Turkish traditional medicine, in rats
}

\section{Research Article}

Volume: 1, Issue: 3

December 2017

Pages: 71-75

\section{Gülbin Șennazlı ${ }^{*}$ Erdal Matur ${ }^{2}$}

1. Istanbul University, Veterinary Faculty, Department of Pathology, Avcilar, Istanbul.

2. Istanbul University, Veterinary Faculty, Department of Physiology, Avcilar, Istanbul.

\begin{abstract}
Helleborus orientalis Lam., a member of the family Ranunculaceae, is one of the medical plants, which is naturally grown in Turkey flora. Roots of Helleborus orientalis are used for the treatment of bronchitis, pneumonia or other inflammatory disease in farm animals by implanting subcutaneously in the public. This study was planned to investigate the histopathological changes in liver, heart and skin of rats that were applied plant raw material (PRM), water extract (WE) and methanol extracts (ME) of Helleborus orientalis subcutaneously. Foci of abscess were determined in the subcutaneous tissue of all 3 experimental groups at the end of 10-day experimental period. During the histopathological examination of the liver, parenchymatous degenerations were observed in the hepatocytes of PRM and WE group rats, and caseous necrosis were determined in the liver of all rats in ME group. Hyaline degenerations were observed in myocard cells of the rats in PRM and WE groups. Furthermore, hyaline degenerations and edema occurred locally in the myocard of all animals in ME group. Vacuolar zones were found in certain myocard cells. The results of the present study indicate that long-term use of Helleborus orientalis might be harmful due to its pathological effects on some tissue.
\end{abstract}

Received: 05.12.2017

Accepted: 28.12.2017

Available online : 29.12.2017
Keywords: Helleborus orientalis Lam, Rat, Histopathology, Turkish folk medicine.

DOI: $10.30704 /$ http-www-jivs-net.362297

To cite this article: Sennazlı, G, \& Matur E. (2017). The Pathological and clinical effects of Helleborus Orientalis used in Turkish traditional medicine, in rats. Journal of Istanbul Veterinary Sciences, 1(3), 71-75. Abbreviated Title: J Ist Vet Sci

\section{Introduction}

Helleborus orientalis Lam., a member of the family Ranunculaceae, is a medical plant, which is naturally grown in Turkey flora. It is called karaca otu, dana kıran, çöplemecik kökü or bohça otu in the public (Malkoç, 1967). In some regions of Turkey, Helleborus orientalis have been used in the past for the treatment of farm animals by implanting the roots of the plant subcutaneously (Kantemir and Temelli, 1963). It has been stated that this original method described above is used in Romania (Bogdan et al., 1990). Furthermore it has been reported that Helleborus species have been used traditionally for the treatment of tympanites in Spain (Blanco et al., 1999), for the treatment of inflammatory diseases and pneumonia of sheep and pigs, and distemper of dogs in Italy until recently (Uncini Manganelli et al., 2001). Research investigating the medical properties of Helleborus species (Meng et al., 2001) shows that Helleborus foetidus possesses insecticide property (Pascual-Villalobus and Robledo, 1998), and Helleborus niger has mutagenic effects (Büssing and Schweizer, 1998) as well as it can be used as an adjuvant therapy in the treatment of tumour patients. Moreover it has been stated that extracts obtained from Helleborus purpurascens have similar properties to immune suppressive substances used in transplantation (Ternes et al., 1999) and can be used for the treatment of rheumatism and autoimmune diseases (Linke et al., 1998). Although there is little information about the usage of Helleborus orientalis in modern medicine, it has been reported that the plant possesses anti-inflammatory and antinociceptive activity (Erdemoglu et al., 2003). 
It has also been reported that Helleborus species has some toxic effects such as vomiting, diarrhoea and paralysis, differing from the above mentioned advantageous features of the plant (Holliman and Milton, 1990; Bogdan et al., 1990). We have observed that sometimes the implantation period of the plant's roots was limited to a day and sometimes the roots of the plant was left in the skin until they comes out by themselves. Therefore both short-term and long-term applications are carried out in the public. Short-term application of the plant causes changes in blood parameters (Matur et al., 2003). Long-term use of the plant shows that permanent changes in tissue may occur in addition to physiological changes. However, a survey of the literature revealed that the pathological effects of Helleborus orientalis on tissue have not been studied yet. The existing knowledge mostly includes clinical findings or toxicological observations.

Therefore, in order to use this plant in modern medicine, it must be determined whether or not it causes any pathological changes in organs. The current paper was undertaken to investigate the clinical, histopathological and physiopathological changes in the liver, heart and skin of rats applied the extracts of Helleborus orientalis subcutaneously.

\section{Materials and methods}

\section{Plant material}

Plant materials were collected from Kıyıöy (Kırklareli / Turkey) during November and December 2002. Helleborus orientalis was collected during its vegetative stage. Authenticated voucher specimens were deposited in the Herbarium of Faculty of Pharmacy, Istanbul University. Herbarium no: ISTE. 81380. Roots and rhizomes of the plant were used in the study.

\section{Preparation of plant material}

Roots and rhizomes of Helleborus orientalis were ground, after they had been dried under shade at room temperature. The powdered plant material was homogenized for 10 minutes with 12 times the substance's weight $(\mathrm{w} / \mathrm{v})$ petroleum ether in ultraturrax, and was filtered through filter paper. After the homogenization was repeated three times, the petroleum ether was evaporated to obtain plant material free from oil (Wissner and Kating, 1971). The powdered plant material was extracted with 20 fold the substance's weight $(\mathrm{w} / \mathrm{v})$ methanol in soxhlet apparatus to extract the components soluble in alcohol (Cioaca and Cucu, 1974). Aqueous extraction of powdered plant material was done with its 8 fold weight boiling distilled water (Zhang et al., 1999). The solvents used during extraction were removed completely via vacuumed evaporator (Cioaca and Cucu, 1974). 1\% solutions of the obtained extracts and the powdered form of the plant were prepared with distilled water (w/v).

\section{Animals}

A total of 40 Wistar albino female rats, each weighing about 180 gr, were used. The animals purchased from Experimental Medicine Research Centre of Istanbul University were left undisturbed for 1 week for their habituation to the environmental conditions. The animals were divided into 4 groups of 1 control and 3 experimental groups with 10 rats in each. Water and food were supplied ad libitum. The animals were examined regularly in order to determine the toxicological symptoms or probable death of an animal. The animals were treated according to the suggested international ethical guidelines for the care of laboratory animals. Ethic Committee of Istanbul University, Faculty of Veterinary Medicine, approved the study. Approval number: 2004-80.

\section{Experimental procedure}

We could not estimate a proper dose since the roots of Helleborus orientalis were reported to be used by inserting into the skin in the public. Therefore, $1 \mathrm{ml}$ of $1 \%$ solutions of powdered plant raw material (PRM), water extract (WE) and methanol extract (ME) were administered subcutaneously to the experimental groups respectively. The dose mentioned above is approximately equal to $55.5 \mathrm{mg} / \mathrm{kg}$. One $\mathrm{ml}$ of distilled water was administered subcutaneously to the control group (C) animals. The injections were made every other day during the 10-day experimental period.

\subsection{Histopathological examination}

Autopsies were performed after the animals were sacrificed under ether anaesthesia at the end of the experimental period. Tissue collected for histopathological examination were fixed in 10 percent neutral buffered formalin dehydrated embedded in paraffin, sectioned at $4 \mu \mathrm{m}$, stained with hematoxylineosin (HE) and investigated under light microscope (Luna, 1968). 


\section{Results}

\section{Clinical findings}

During the experimental period none of the animals died and any toxic symptom was not observed. However clear abscesses were determined in various points of the skin of PRM, WE and ME group animals during the last one-third of the experimental period. Any abscess was not observed in the control group.

tissue of a PRM group rat (H.E. X4).

\section{Histopathological findings}

Foci of abscess in different size formed by intense neutrophil leukocytes infiltration were determined in subcutaneous tissue of ME and WE group rats. Around these foci, neovascularization and demarcation areas eventuated from neutrophil leukocytes and macrophages were observed. Unabsorbed plant particles in the foci of abscess (Figure 1), and foreign

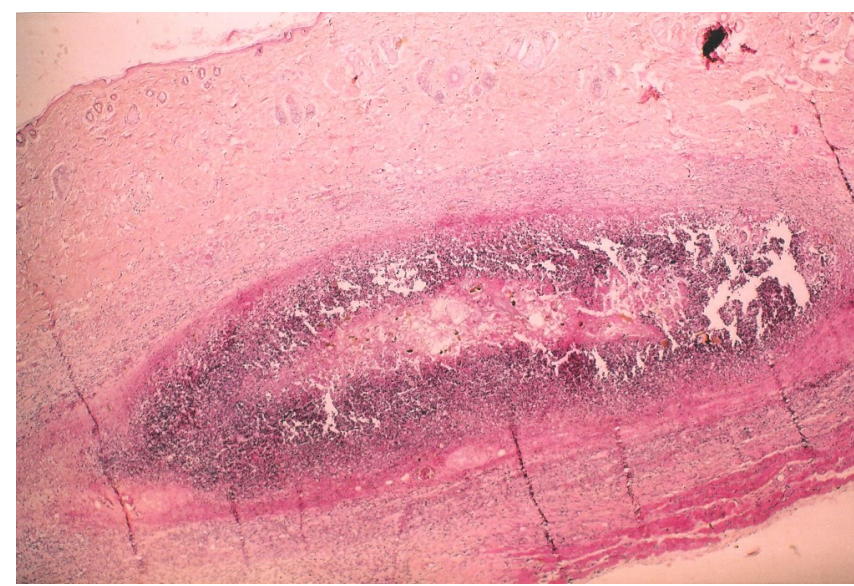

Figure 1: Skin: Foci of abscess in the subcutaneous tissue of a PRM group rat (H.E. X4).

body giant cells and immature fibrous connective tissue in demarcation areas were determined in PRM group rats. Parenchymatous degeneration in the hepatocytes

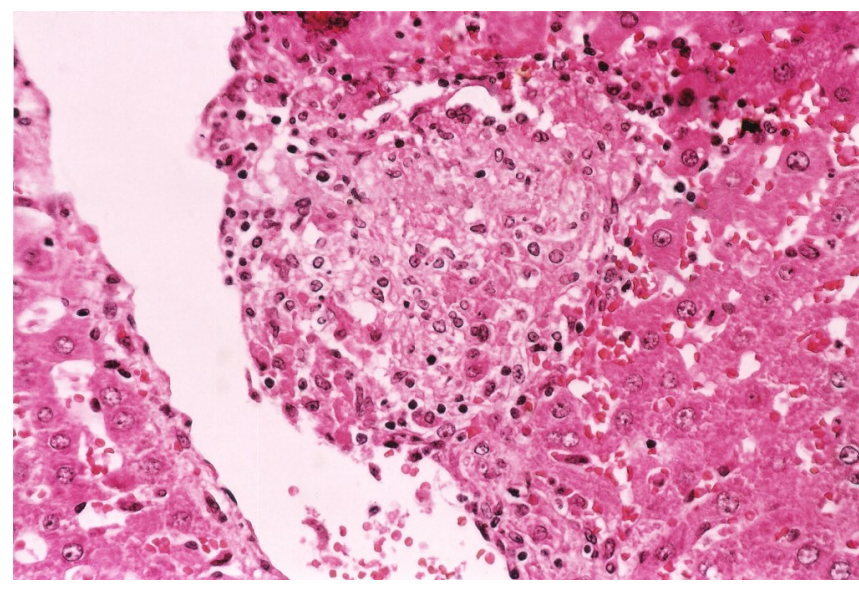

Figure 2: Liver: Focal coagulation necrosis in liver of a PRM group rat (H.E. X40). and islets formed of 2 or 3 degenerative hepatocytes were observed during the histopathological examination of the liver of rats in PRM and WE groups. Focal coagulation necrosis (Figure 2) and mononuclear

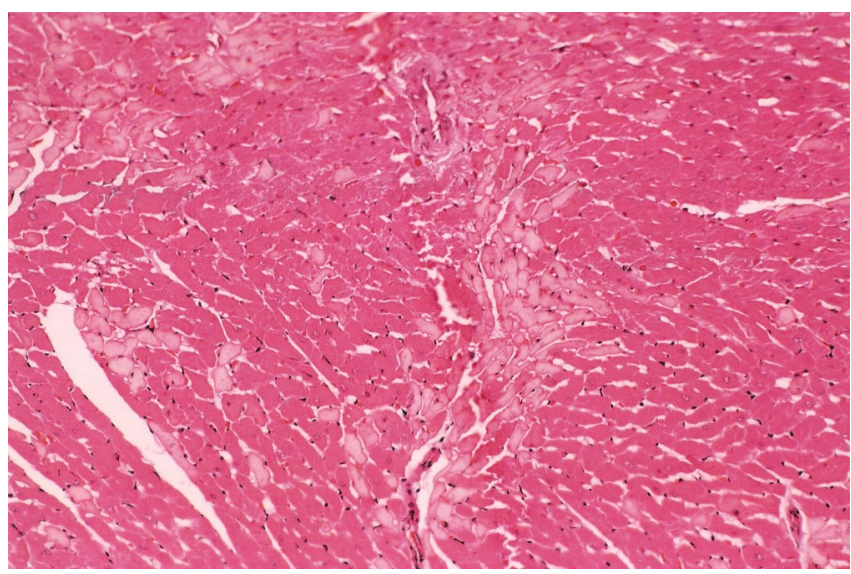

Figure 3: Heart: Diffuse hyaline degeneration in myocardial cells of a WE group rat (H.E. X40).

cell infiltration in periportal areas were found in three rats from both PRM and WE groups. Foci of caseous necrosis surrounded by mononuclear cells and fibrous connective tissues were determined in the liver of all rats in ME group. During the histopathological examination of the heart, compact hyaline structures in certain myocardial areas and diffuse hyaline degeneration in myocardial cells were observed in PRM and WE group rats (Figure 3). Hyaline degenerations together with edema occurred locally in the myocard of rats in ME group. Furthermore vacuolization were found in certain cells.

\section{Discussion}

The histopathologic findings of the current study indicate that foci of abscess in different size eventuated in the subcutaneous tissues of PRM, WE and ME group rats. Kantemir and Temelli (1963) also reported that Helleborus orientalis implanted subcutaneously to the farm animals cause abscess. However it has not been explained whether the abscess observed in the implantation area occurred due to the mechanical effect of the plant's root or the active substances in the plant. Abscesses that occurred in PRM and also in WE and ME demonstrate that abscesses in the implantation area does not only occur due to the mechanical effect of the plant but also result from active substances in the plant. Therefore it can be said that if the plant itself or its products extracted with water or methanol, are in contact with tissues for a long time, it may cause irritation. 
Histopathologic findings observed in the liver of the rats in PRM, WE and ME groups indicate that Helleborus orientalis cause degenerative and necrotic changes in liver. One of the most important finding observed in the current study is that focal coagulation necrosis determined only in three rats from both PRM and WE groups whereas caseous necrosis was determined in the liver of all rats in ME group. These findings show that the damage determined in the liver of ME group rats are more severe than those of the PRM and WE group rats. It is obvious that the reason for the severe damage observed in ME group is the substances, which are soluble in methanol, in the roots and rhizomes of Helleborus species. Since the absorption of the methanol soluble substances is limited by implantation method used in public, the negative effects of Helleborus species on liver is not going to be so severe especially in shortterm use of the plant.

Histopathological examination of the heart shows that hyalinization and diffuse hyaline degeneration exist in the myocardium cells of PRM and WE group rats. Hyaline degeneration together with edema was observed locally in the myocard of ME group rats.

Blanco, E., Macia, M. J., \& Morales, R. (1999). Medicinal and veterinary plants of El Caurel (Galicia, northwest Spain). Journal of Ethnopharmacology, 65, 113-124.

Bogdan, I., Nechifor, A., Başea, I., \& Hruban, E. (1990). From the Rumanian folk medicine: unspecific irritating therapy by transcutaneous implantation of Helleborus purpurascens Fam. Ranunculaceae in farm animals. Deutsche Tierarztliche Wochenschrift, 97, 525-529.

Büssing, A., \& Schweizer, K. (1998). Effects of a phytopreparation from Helleborus niger on immunocompetent cells in vitro. Journal of Ethnopharmacology, 59, 139-146.

Cioaca, C., \& Cucu, V. (1974). Quantitative determination of hellebrin in the rhizomes and roots of Helleborus purpurascens W.et K. Planta Medica, 82, 250-253.

Duncan, J. R., \& Prasse K. W. (1986). Veterinary laboratory medicine clinical pathology 2nd ed, Ames Iowa, US: Iowa State University Press.

Erdemoglu, N., Küpeli, E., \& Yeşilada, E. (2003). Antiinflammatory and antinociceptive activity assessment of plants used as remedy in Turkish folk medicine. Journal of Ethnopharmacology, 89, 123-129.

Holliman, A., \& Milton, D. (1990). Helleborus foetidus poisoning of cattle. Veterinary Record, 783, 339-340.
(Blanco et al., 1999) have been reported that cardioactive glycosides found in the roots and rhizomes of Helleborus species have toxic effects on heart. The results of the current study indicate that Helleborus orientalis causes pathological changes in heart. The damage observed in the heart of PRM and WE group rats may result from the plant's hellebrin glycoside that is soluble in water (Malkoç, 1967). However, the observation of pathological changes in the heart of ME group rats shows that methanol soluble compounds are also effective.

The results of the current study reveal that although Helleborus orientalis used in traditional medicine has curing characteristics, it causes local irritation and causes significant pathological changes in liver and heart. Therefore it can be said that the long-term application of this plant preferred by public for the treatment of farm animals occasionally, might be harmful. The harmful effects of Helleborus orientalis determined in the current study should be taken into consideration and the treatment protocol should be organized according to this.

Kantemir, I., \& Temelli, E., (1963). Comparative studies with Helleborus orientalis L. Arzneimittelforschung, 79, 10121013.

Linke, S., Dufter, C., Kerek, F., Jung, M., Watzlik, A., Jung, T., Opelz, G., \& Terness, P. (1998). Functional characterization of HP12: A novel immunosuppressant purified from Helleborus species. Transplantation Proceedings, 96, 4106 $-4107$.

Luna, L.G. (1968). Manual of histologic staining methods of the Armed Forces Institute of Pathology, 3rd ed. New York US: Mc Graw-Hill Book Company.

Malkoç, G. (1967). Pharmacognosic investigations in Helleborus orientalis Lam var. Hirsitus (schiffn) hay. plant. Ph.D. Thesis , Istanbul University, Istanbul, Turkey.

Matur, E., Özcan, M., Turan Çıraklı, Z., \& Küçükyalçın, E. (2003). Bioactivity examination of Helleborus orientalis plant in rats. 1. Effects on some physiological parameters. Indian Veterinary Journal, 80, 1239-1244.

Matur, E., Turan Çıraklı, Z., Özcan, M., Kadıköylü, Ç. (2004). Bioactivity examination of Helleborus orientalis plant in rats. 2. Effects on some serum parameters. Indian Veterinary Journal, 81, 387-391.

Meng, Y., Whiting, P., Sik, V., Rees, H. H., \& Dinan, L. (2001). Ecdysteroids and bufadienolides from Helleborus torquatus (Ranunculaceae). Phytochemistry, 13, 401-407. 
Pascual-Villalobos, M.J., Robledo, A. (1998). Screening for anti -insect activity in Mediterranean plants. Industrial Crops and Products, 8, 183-194.

Terness, P., Dufter, C., Linke, S., Kerek, F., Jung, T., Watzlik, A., Opelz G. (1999). HP12: A highly purified Helleborus species extract strongly potentiates the T-cell suppressive effect of cyclosporine A. Transplantation Proceedings, 97, 1174-1175.

Uncini-Manganelli, R. E., Camangi, F., Tomei P. E. (2001). Curing animals with plants: traditional usage in Tuscany (Italy). Journal of Ethnopharmacology, 34, 171-191.
Wissner, W., Kating, H., (1971). Studies on the hellebrin content in subterranean organs of Helleborus species. Planta Medica, 20, 344-349.

Zhang, J., Meng, Z., Zhang, M., Ma, D., Xu, S., Kodama, H., (1999). Effect of six steroidal saponins isolated from Anemarrhenae rhizoma on platelet aggregation and hemolysis in human blood. Clinica Chimica Acta. 845, 7988. 